\title{
Wide local resection of sacral chordoma through posterior midline approach
}

\author{
Md. Anowarul Islam, Dipendra Mishra, Santosh Batajoo and Manish Shrestha
}

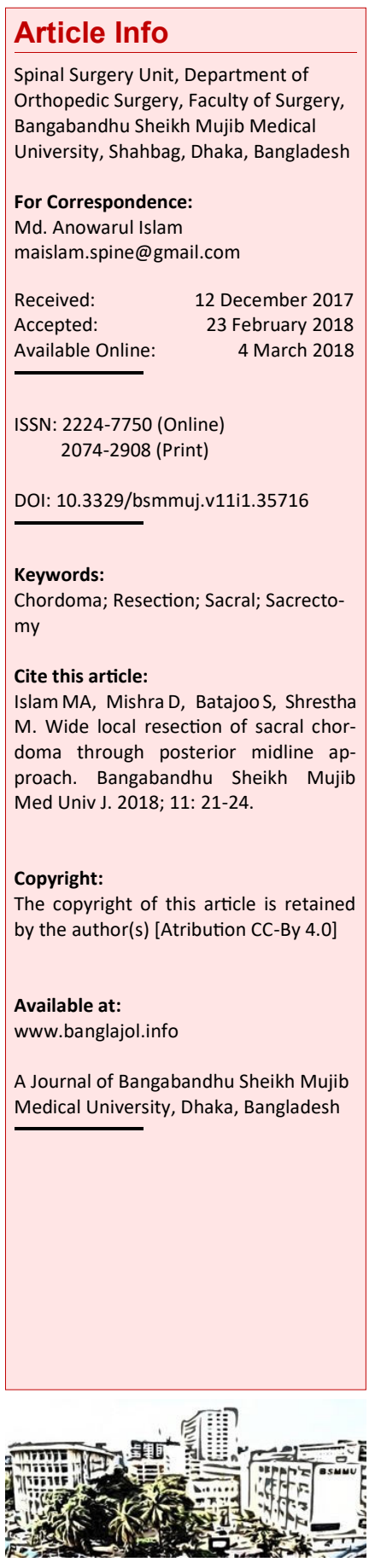

\section{Abstract}

This study was performed in 21 patients with sacral chordoma from July 2008 to June 2017 and posterior surgical approach was used for resection. Out of 21 patients, 12 had done subtotal sacrectomy and the remaining 9 had done partial sacrectomy. Their follow-up periods were at least five years. Operative time ranged between two to four hours. All patients recovered well from operation and two to five units of blood transfusion were needed for each. After operation, majority of the patients developed some bowel and bladder dysfunction and five patients developed wound infection. During the follow-up, two patients had tumor recurrence and one patient expired two years after operation. The remaining 18 patients were tumor-free at the 5 -years follow-up. Wide surgical resection via the posterior midline approach could be a good management plan for the sacral chordoma. However, complete removal with surgical margin varies according to the location of the tumor.

\section{Introduction}

Chordoma is a slowly growing, histologically low-grade rare malignant tumor, arising from the remnants of the notochord which is located in the axial skeleton.1-3 Most of the chordomas develop in the sacrococcygeal region (40-50\%), base of the skull $(35-40 \%)$, and vertebral bodies $(15-20 \%) . \underline{4}$

The diagnosis is always delayed for most of the patients. The chordoma always destroys the bone, and invades into the surrounding soft tissue. It is locally aggressive low-grade malignant tumor. $\underline{5}$

As it has poor sensitivity to radiotherapy and chemotherapy, complete surgical excision is required.6-8 To decrease the local recurrence of the sacral chordoma, dissection should be done as complete as possible.? Wide local resection is still the best choice of treatment for sacral chordoma though majority of the patients subsequently develop significant complications. 10 The most common dreadful complications are neurological involvement and disability, according to the level of involvement of tumor, extent and severity of neurological deficit appear.11 Complete surgical excision is the mainstay of treatment as chordoma is insensitive to chemotherapy.12 Combined anterior and posterior approaches have been used by most of the surgeons. By the anterior approach, the visceral organs can be protected. The tumors can be dissected out directly whereas better exploration and protection of neural elements with bone reconstruction in total sacrectomy better achieved by the posterior approach. The good option is the combined approach which is extensive surgery where needs a prolonged operative time and recovery time. $\frac{3,13,14}{1}$ The goal of this study is to observe the outcome of patients with sacrococcygeal chordoma in relationship to local recurrence by performing wide resection through posterior approach.

\section{Materials and Methods}

Twenty-one patients of sacral chordoma treated at the spine unit, Department of Orthopedic Surgery, Bangabandhu Sheikh Mujib Medical University and other private hospital in Dhaka city from July 2008 to June 2017 were included. A prospective interventional study with selective inclusion criteria was carried out. Patients with the history of previous surgery were excluded from the study. All the patients were followed-up for 5 years after operation but one patient died after 2 years of surgery. They were evaluated accordingly.

\section{Study procedure}

Eighteen patients attended the unit with pain and a mass in sacral region. Among them, 10 had neurological deficit. The remaining three patients came with only sacral mass without 

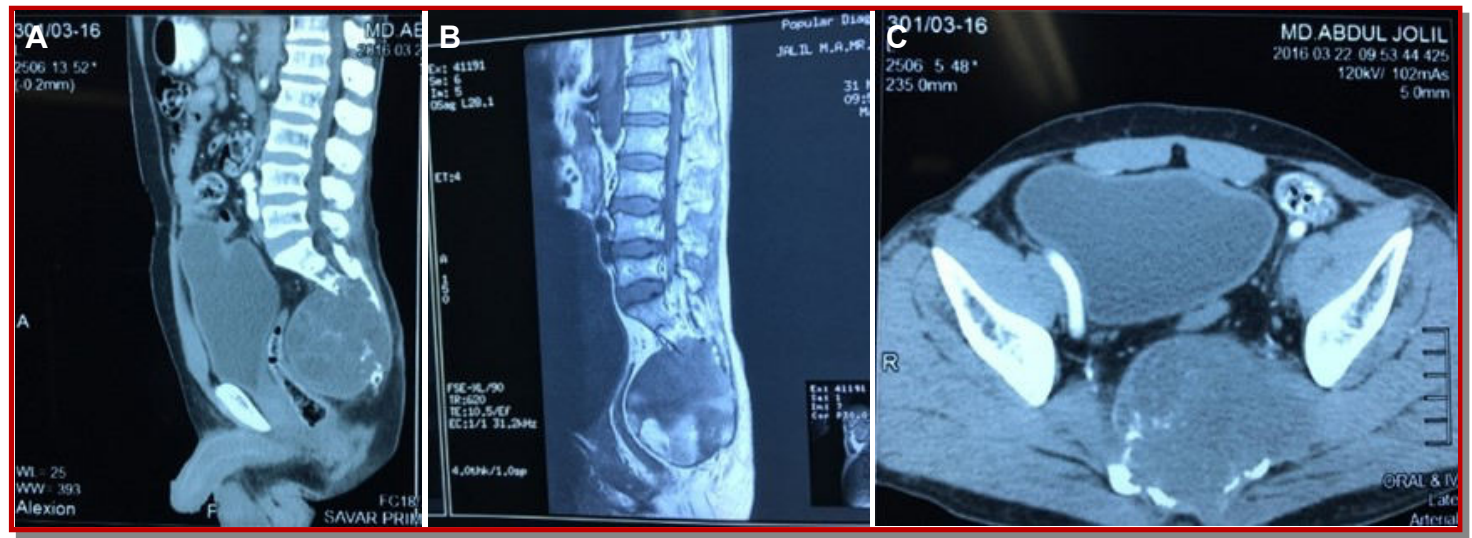

Figure 1 : Pre-operative sagital CT scan showing involvement of tumor up to S2 (A), sagital (B) and axial MRI of sacrococcygeal spine shows involvement of the tumor up to S2 with compression of cauda equina in sacral canal (C)

any pain or neurological deficit. Diagnosis made on the basis of physical examination and investigations including plain radiograph and MRI (Figure 1). All patients undergone incisional biopsy through posterior approach for histological confirmation. According to the surgical staging by Enneking et al. (1980) $\underline{15}$ all the patients were in Stage IB.

\section{Operative technique}

The surgery was carried out under general anesthesia in all patients in prone position. A midline longitudinal incision made centering the tumor mass which extents about three vertebral levels above and up to the tip of coccyx with excision of the scar of the biopsy which was previously performed. With electrocautery, the dissection was done through fascia and muscles up to the bones, to make adequate tumor free margin by preserving the gluteal muscles up to $2-3 \mathrm{~cm}$. After cutting the skin and deep fascia, spinous process and lamina of L3, L4 and L5 were identified. The posterior part of both iliac crest, both iliac wings and ala of sacrum by identifying the posterior superior and posterior inferior iliac spine were exposed. Then, in front of the body of lower lumbar vertebrae, sacrum and under the iliac crest, rolled gauze swabs were packed. The dissection was done along the posterior part of both iliac wings to expose the both sciatic notch. The superior gluteal vessels were protected at the sciatic notch. Osteotomy was done carefully by protecting the vital organs. Laminectomy was done at L3 or L4, by identifying the upper limit of the tumor per-operatively. During dissecting out the tumor mass, all nerve roots were identified. Then, image intensifier was used to reevaluate the margin of resection carefully in relationship of bone involvement between intraoperative findings and MRI. The posterior part of the iliac crest, normal vertebral body and the disc above the lesion were cut by high speed diamond burr and osteotome. The sacrum and the tumor mass were rotated posteriorly by using bone hook. The tumor was made free from the sacral nerves and feeding vessels which was cautiously dissected (Figure 2). The L5 nerve root was identified and protected which passes anterior to the ala of sacrum, by which identification of the sacral plexus was done. The sacral plexus was explored on both sides. The identi -fication of sacrospinal and sacrotuberous ligaments was done on both sides and cut by electrocautery.

In the patient who underwent partial sacrectomy, instrumentation was not done. The skin and soft tissue were repaired. Pressure dressing was applied. On the 3rd post-operative day, dressing was removed and surgical wound was inspected to see any wound complication which was recorded. After that dressing was re-applied. Neurological reevaluation was done. The plain radiograph was done after the operation to see the osteotomy site,

\section{Follow-up}

The stitch removal was done at 14 days after the operation. Histopathological diagnosis of the tumor mass as well as tumor margin were done. Ventral aspect of the tumor was tumor free. Radiotherapy at the average dose of 3,500-4,500 Gy was given to the patient who did not have tumor free margin to prevent the local tumor recurrence. At every followup, the physical examination as well as neurological reassessment of the lower limbs, anal, perianal area, digital rectal examination and plain X-ray of chest and local area were done. For the first two years of operation, followed-up done in every three months interval, then at six months interval. MRI of the lumbosacro-coccygeal spine was done at six months interval during the first two years, then once in every year for subsequent follow-up.

\section{Results}

Subtotal sacrectomy was done in 11 (52.4\%) patients tumor involved up to S2 and in one patient up to S1 but 9 patients underwent partial sacrectomy tumor involvement up to S3 level. The operative time 


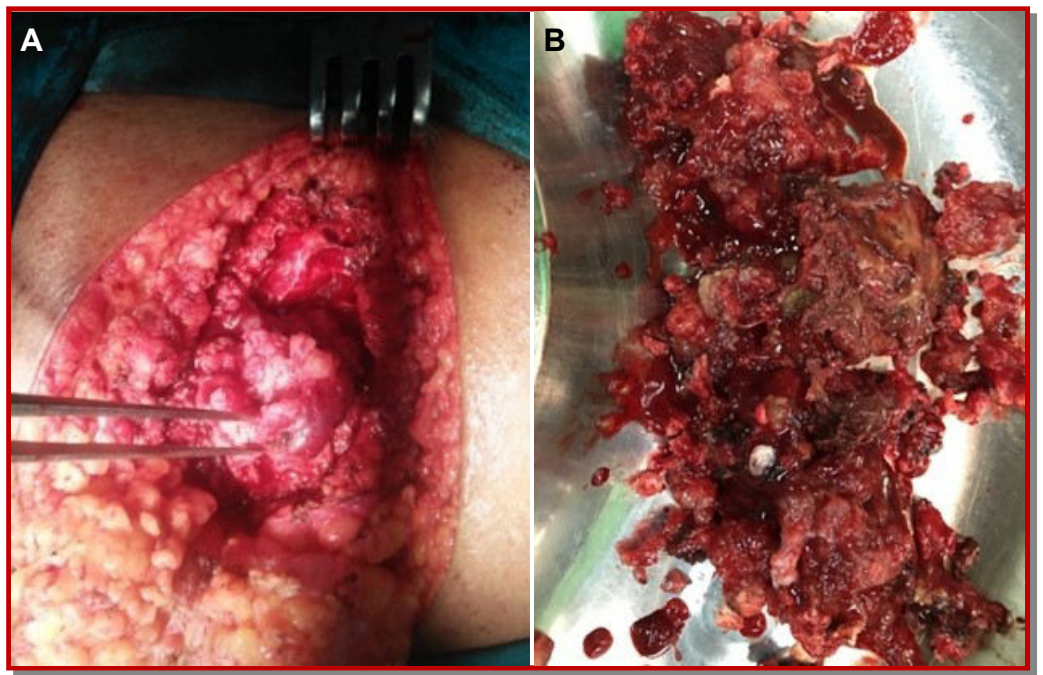

Figure 2: Per-operative image shows tumor mass during dissection (A) after excision of tumor when kept in kidney tray (B)

Table I

\begin{tabular}{|c|ccc|}
\hline \multicolumn{4}{|c|}{ Level of involvement with 5-years recurrence rate and mortality } \\
\hline Up to level & No. of patients & Recurrence at 5-years & Mortality \\
\hline L5 & 0 & 0 & 0 \\
S1 & 1 & 1 & 1 \\
S2 & 11 & 1 & 0 \\
S3 & 6 & 0 & 0 \\
S4 & 2 & 0 & 0 \\
S5 & 1 & 0 & 0 \\
\hline
\end{tabular}

ranged between two to four hours (average 3 hours). Average peri-operative blood loss was 1,000 $\mathrm{mL}$. The average post-operative drainage collection was around $400 \mathrm{~mL}$. Two to five bags of blood transfusion needed for all patients. Infection was present in five patients. After the operation, 12 patients developed neuropathic pain. Pain severity was measured by visual analog scale which was between 0.5 and 3 at 5 months of operation. According to histopathological report, eight patients had tumor free margin definitely and 13 patients had marginal tumor free margin at its ventral aspect where tumor contamination was not found and margins at the gluteal muscles were less than $2 \mathrm{~cm}$. These 13 patients received radiotherapy. Significant complication was not found in the patients except one who developed radiation colitis. The patient was 52 years old male on whom sacrectomy was done up to S2 level presented with lower abdominal pain and bleeding per rectum improved well with the symptomatic and supportive treatment. No tumor recurrence was found at two-years follow-up. One female patient showed local recurrence of tumor after 3 years and reoperation was done successfully. Two patients showed local tumor recurrence with distant metastasis at 5years follow-up in whom one patient died due to distant metastasis of tumor in lungs and bones. The distribution of level of involvement, recurrence rate and mortality is shown in Table I.

\section{Discussion}

The involvement of tumor in the majority of patients of this study was up to the level of S2, S3 and then S1. It is similar to the study of Fuchs et al. (2005) who showed the majority involved in the S2, S3 and then S1.16 Chordoma has poor response to chemotherapy and radiotherapy. So, surgical excision is the only reliable treatment.17Tumor free period was shorter in patients with gross tumor contamination during the surgery than who had done wide resection. To decrease the recurrence rate and to maximize the tumor free period, wide resection was done through the posterior approach. 18 Through the posterior approach, all visceral organs and vessels were protected by a large number of gauge packing in front of the sacrum and body of the lower lumbar vertebra from bone cutting with the diamond burr and osteotome. It also prevents intraoperative bleeding by tamponade effect on the intrapelvic venous plexus. $\underline{19}$ Similar technique was used successfully in this study and none had visceral organs or great vessels injury during bone cutting through posterior approach.

In this study, 11 patients underwent subtotal sacrectomy where tumor extended up to S2 and in one patient up to S1. Partial sacrectomy was done in 9 cases with the involvement below S2. In our patients, the tumor free period and tumor recurrence rate were similar to other studies. $90.5 \%$ of our patients were tumor free at the 5-year follow-up which is similar to the study conducted by Asavamongkolkul and Waikakul (2012) which was $86 \% .19$ In this series, there is $9.5 \%$ tumor recurrence at 5-years of follow-up and $4.8 \%$ patient who required second operation for recurrence which was similar to the study of Pietro et al. (2010)므

In case of patients of this study, there was no such complication like pulmonary embolism, deep vein thrombosis, bowel and bladder injuries but bowel bladder dysfunction was found $12 \%$ in the study of Pietro et al. (2010)르 In the study with review of 21 cases conducted by Samson et al. (1993) metastasis was found in $5 \%$ cases, $\underline{21}$ which is similar to our study $(4.8 \%)$. The important issue is to remove the lesion as much as possible and to spare nerve roots as possible and the use of adjuvant radiation therapy.

The role of radiation is inconclusive. However, the radiotherapy was given in 13 patients $(61.9 \%)$ in this study who had marginal tumor free margin to prevent the local recurrence. Other studies suggest 
that the adjuvant radiotherapy may prolong the disease free interval and decrease the symptom of recurrent lesion. .2 Most authors have agreed that the posterior approach is satisfactory for the lesions at the third sacral segment or caudal but have advised combined anterior and posterior approach. $5,23,24$ In our experience, the posterior approach is satisfactory. It has less complications with the advantage of shorter operative time (average 3 hours), blood loss (average 1,000 mL) and less morbidity. But in the study of Asavamongkolkul and Waikakul (2012), 19 the average operating time was 6.4 hours and the blood loss was $1,238 \mathrm{~mL}$, as most of the cases was total sacrectomy.

\section{Conclusion}

Through posterior approach wide resection of chordoma of sacrum is a good option for removing of tumor as much as tumor free and by this less blood loss can be ensured during bone cutting by large amount of gauge packing close to the anterior aspect of sacrum and body of lower lumbar vertebra.

\section{References}

1. Azzarelli A, Quagliuolo V, Zucali R, Mazzaferro V, Dossena G, Gennari L Chordoma: Natural history and treatment results in 33 cases. J Surg Oncol. 1998; 37: 185-91.

2. Mindell ER. Chordoma. J Bone Joint Surg. 1981; 63 : 501-05.

3. Sahakitrungruang C, Chantra K. One-staged subtotal sacrectomy for primary sacral tumor. Ann Surg Oncol. 2009; 16: 2594.

4. Unni KK, Inwards CY. Dahlin's bone tumors: General aspects and data on 11,087 cases. $5^{\text {th }}$ ed. Philaelphia, Lippincott-Raven, 1996, pp 291-305.

5. Huvos AG. Bone tumors, diagnosis, treatment and prognosis. 2nd ed. Philadelphia, W.B. Saunders. 1991, pp 599-624.

6. Fuller DB, Bloom JG. Radiotherapy for chordoma. Int J Radiat Oncol Biol Phys. 1988; 15: 331-39.

7. Chandawarkar RY. Sacrococcygeal chordoma. Review of 50 consecutive patients. World J Surg. 1996; 20: 717-19.

8. Bethke KP, Neifeld JP, Lawrence WJ. Diagnosis and management of sacrococcygeal chordoma. J Surg Oncol. 1991; 48: 232-38.

9. Yang H, Zhu L, Ebraheim NA, Liu X, Castillo S, Tang T, Liu J, Cui H. Analysis of risk factors for recurrence after the resection of sacral chordoma combined with embolization. Spine J. 2009; 9: 97280 .
10. Samson IR, Springfield DS, Suit HD, Mankin HJ. Operative treatment of sacrococcygeal chordoma: A review of twenty-one cases. J Bone Joint Surg Am. 1993; 75: 1476-84.

11. Fourney DR, Rhines LD, Hentschel SJ, Skibber JM, Wolinsky JP, Weber KL, Suki D, Gallia GL, Garonzik I, Gokaslan ZL. Enblock resection of primary sacral tumors: Classification of surgical approaches and outcome. J Neurosurg Spine. 2005; 3: 111-22.

12. Cheng EY, Ozerdemoglu RA, Transfeldt EE, Thompson JrRC. Lumbosacral chordoma. Prognostic factors and treatment. Spine 1999; 24: 1639 45.

13. Ramamurthy R, Bose JC, Muthusamy V, Natarajan M, Kunjithapatham D. Staged sacrectomy: An adaptive approach. J Neurosurg Spine. 2009; 11: 285-94.

14. Waisman P, Kligman M, Roffman M. Posterior approach for radical excision of sacral chordoma. Int Orthop. 1997; 21: 181-84.

15. Enniking WF, Spanier SS, Goodman MA. System for the surgical staging of musculoskeletal sarcoma. Clin Orthop. 1980; 153: 106-20.

16. Fuchs B, Dickey ID, Yaszemski MJ, Inwards CY, Sim FH. Operative management of sacral chordoma. JBJS. 2005; 87: 2211-16.

17. Fuller DB, Bloom JG. Radiotherapy for chordoma. Int J Radiat Oncol Biol Phys. 1988; 15: 331-39.

18. Puri A, Agarwal MG, Shah $\mathrm{M}$, Srinivas $\mathrm{CH}$, Shukla PJ, Shrikhande SV, Jambhekar NA. Decision making in primary sacral tumors. Spine J. 2009; 9: 396-403.

19. Asavamongkolkul A, Waikakul S. Wide resection of sacral chordoma via a posterior approach. Int Orthop. 2012; 36: 607-12.

20. Pietro R, Andrea A, Giuseppe U, Maurizio M, Mario M. Surgical margins and local control in resection of sacral chordomas. Clin Orthop Related Res. 2010; 468: 2939-47.

21. Samson IR, Springfield DS, Suit HD, Mankin HJ Operative treatment of sacrococcygeal chordoma. JBJS. 1993; 75: 1476-84.

22. Cummings BJ, Hodson DI, Bush RS. Chordoma: The results of megavoltage radiation therapy. Int J Radiat Oncol Biol Phys. 1983; 9: 633-42.

23. Sung HW, Shu WP, Wang HM, Yuai SY, Tsai YB. Surgical treatment of primary tumors of the sacrum. Clin Orthop. 1987; 215: 91-98.

24. Wuisman P, Harle A, Matthiass HH, Roessner A, Erlemann R, Reiser M. Two stage therapy in the treatment of sacral tumors. Arch Orthop Trauma Surg. 1989; 255-60. 